\title{
Research Status on the Collapse Mechanism and Prevention Measures of Mega Composite Structural Systems
}

\author{
Wei Zhang \\ Hunan Baili Engineering SCI\&TECH CO., LTD, Yueyang 414003, China.
}

\begin{abstract}
Mega composite structural system presents wide application prospects in high-rise and super high-rise buildings. However, research concerning the important issues of the seismic behavior, collapse mechanism, and prevention from progressive collapse for such new structural systems under severe earthquakes is quite limited. This paper will summarize the current research status, followed by the discussions on the collapse and prevention mechanisms of high-rise and super high-rise mega composite structural systems under severe earthquakes, the theoretical basis on progressive collapse mechanisms, numerical simulation techniques, and test methods. The failure modes of high-rise mega composite structures were studied firstly, followed by the collapse mechanisms and the associated criteria and indices. In addition, a new numerical technique for simulating the non-linear structural collapses considering large deformations will be presented, along with the relevant test results. This study shows that analysis method, damage accumulation model, failure criteria, appropriate preventive measures, and improved collapse experimental verification methods are all important seismic design considerations for high-rise and super high-rise mega composite structures. Based on the study results, recommendations for collapse and prevention mechanisms of high-rise buildings are proposed.
\end{abstract}

\section{Introduction}

The concept of mega structures started in the late 1960s. This structural system consists of large members such as mega columns and mega beams which are different from the conventional ones. These main members work with the secondary structure composed of the normal members, forming a combined structural system. Under the new structure system, the main structure is usually the main lateral force system, substructure only bear vertical loads, and is responsible for the force to the main structure. According to the load capacity, mage structures can be divided into four basic types: mega trusses including tube structures, mega frame structures, mega suspended structures, and mega separating tube structures. In recent years, mega structures have been used increasingly in high-rise buildings due to their higher integral rigidity, clearer loading transmission, more regular rules, rapid construction speed, better structure stability, and seismic performance. Selective mega structure buildings are shown in Table 1 and Figures 1-3.

In recent years, Analysis and design of progressive collapse for structure has become a hot research topic. Progressive collapse means that after initial damage is caused by unconventional loads (e.g., strong earthquakes, impact, explosion, fire, et al.) triggering a local failure, other parts of the structure are partially destroyed due to the internal force redistribution [2]. Such chain reaction eventually leads to the collapse of large-scale or overall structure which is disproportionate with the initial local failure. The progressive collapse often leads to heavy casualties and property losses. So, researches on the anti-collapse mechanism of and the prevention methods for the progressive collapse for important buildings have drawn increasing attention. Relevant records show major collapses have been found in commercial and industrial buildings worldwide. With the diversity of structures and the increasing probability of terrorist attacks and accidental events (e.g., earthquakes), the occurrence possibility of progressive collapse is also gradually increasing. Although the design method for such structural system has become matured, past deign codes address the safety design for structural components under normal loads exclusively. Accidental loads have been largely left out. The collapse and prevention mechanisms of a building under accidental loading are still not well understood, which has caused many unavoidable building collapses and economic losses. Research issues related to the collapse analysis and mechanism and prevention measures for structural systems under severe earthquakes have drawn increasingly attention from researchers and engineers. This paper aims to summarize the current research methods with 
Table1. List of selective mega structure buildings

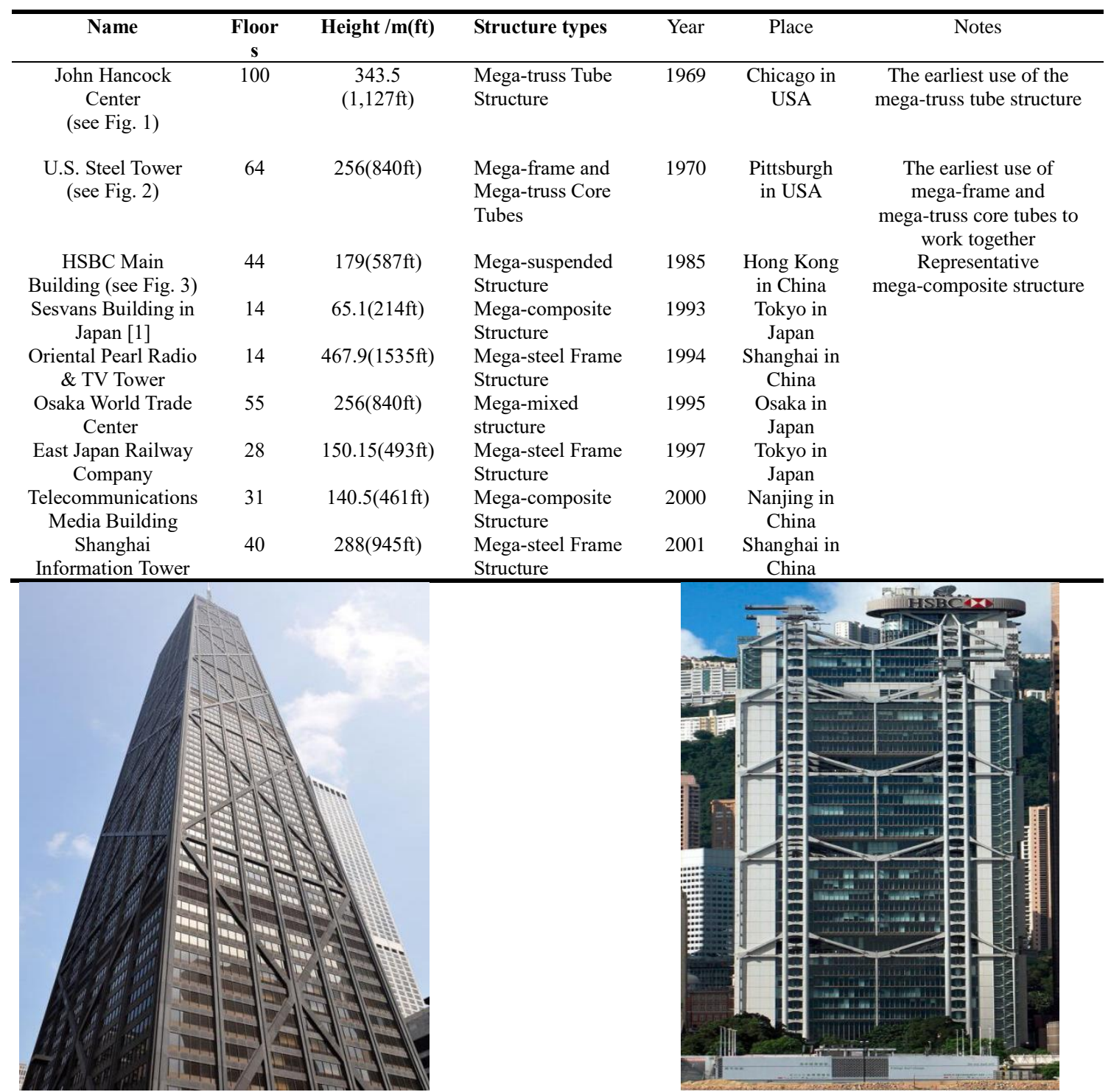

Fig. 1 John Hancock Center

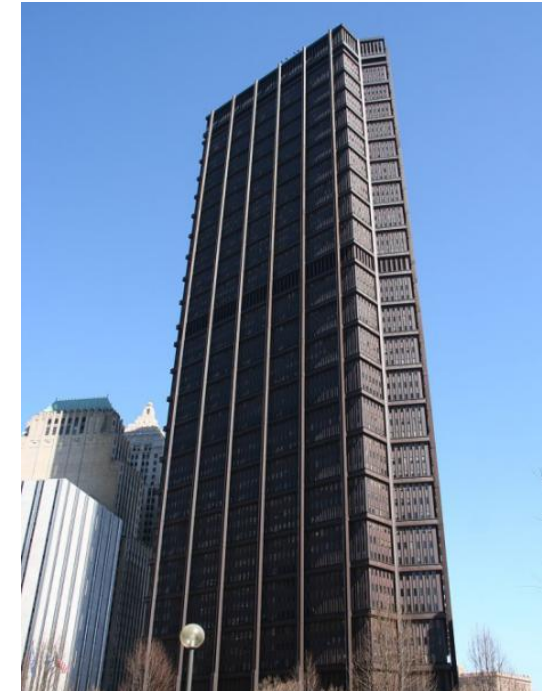

Fig. 2 U.S. Steel Tower
Fig. 3 HSBC Main Building

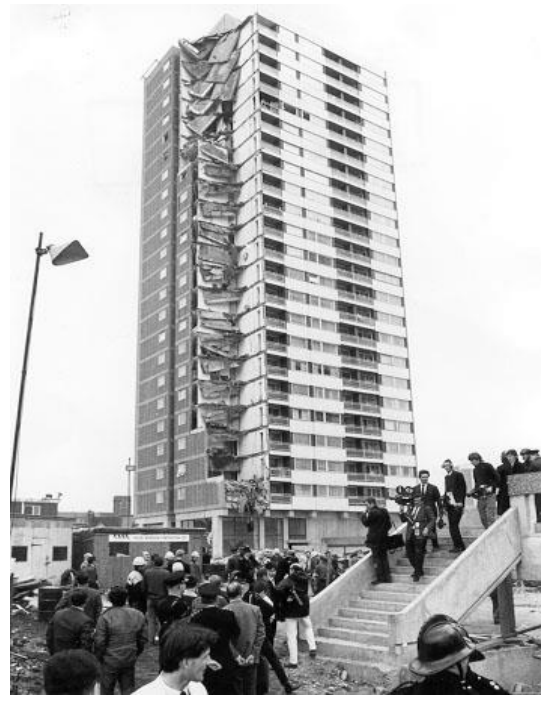

Fig. 4 Ronan Point Collapse 


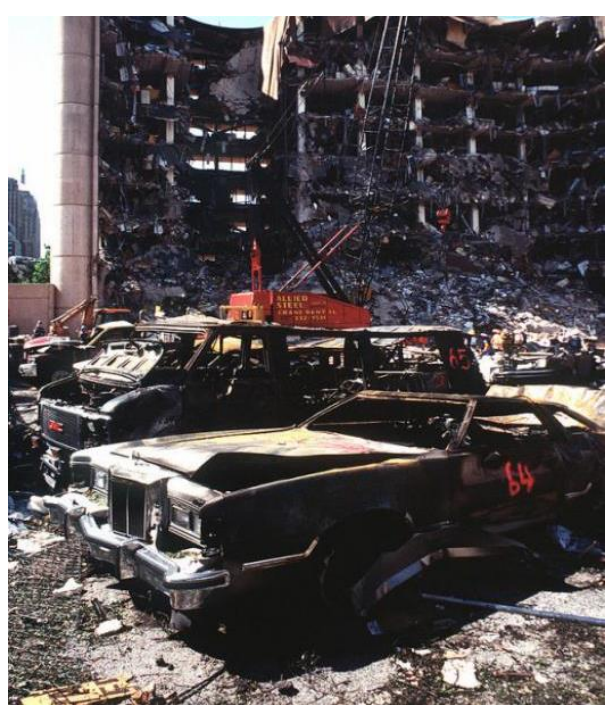

Fig.5 Alfred P. Murrah Building in Oklahoma

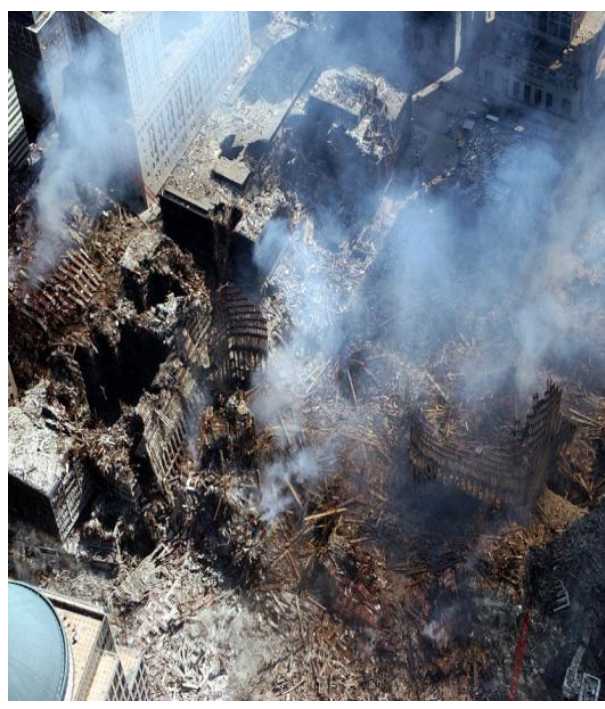

Fig.6 Twin Towers Collapse in New York

comments and to providing a guide for future researches, as related to the relatively new mega composite structural systems which are intended for high-rise buildings.

\section{Theoretical Research}

Since 1960s' , researches on progressive collapse were largely carried out during three particular time periods with each period accompanied by a major collapse event [3]: 1968 collapse of Ronan Point apartment (see Figure 4) in London because of natural gas explosion causing a great concern to progressive collapses for the first time [4]; 1995 collapse of Alfred P. Murrah building in Oklahoma (see Figure 5) due to bombing [5]; and 2001 collapse of the twin towers in New York World Trade Center (see Figure 6) due to the plane hit organized by the terrorists, which culminated in progressive collapse research [6]. As a result, analysis methods and design recommendations on progressive collapse were proposed by researchers along with related specifications and standards, e.g., British code [7], American GSA (General Service Administration) [8], and American DoD (Department of Defense) [9] Specifications and standards for structural anti-collapse appear later in Japan [10]. With the possibility of collapse events and the popular use of mega composite structural systems in modern buildings, the possible significant casualties and enormous economic losses resulting from the potential progressive collapse of a building designed under the conventional design method become more realized. Such possibility is deemed greater for a building higher than $500 \mathrm{~m}$ or a high-rise building demanding special functional requirements. Theoretical and practical researches on collapse mechanisms and prevention measures of high-rise mega composite structural systems under earthquakes are warranted in order to the structural capacity and safety.

Breen studied the progressive collapse of an automobile manufacturing plant at the University of Texas and proposed newer way to alter the load path and improve the structural resistance [11]. He claimed his method would ensure the ductility and continuity of structures. Leyendecker and Ellingwood distinguished accidental load types and suggested three design methods for preventing progressive collapses [12]. Dusenberry summarized a series of measures for strengthening the structural integrity, based on systematic researches on collapsed events, relevant specifications and standards in recent decades, and other important publications [13]. Magnusson studied the failure characteristics of the removed columns from steel frame structures and pointed out that structures without designing to resist progressive collapses possessed certain structural resistance/capacity [14]. Conversely, if the horizontal tensile force were too large in anti-collapse design, the damaged parts would likely leads to whole collapse due to excessive forces. He also indicated that the excessive horizontal tensile force would adversely affect the anti-collapse capacity. Lim and Krauthammer cited three reasons causing the progressive collapse of plane steel frames [15]. Starosse et al. pointed out the following shortcomings of the researches on specifications and standards of structural anti-progressive collapse [16]: (1) The specifications and standards have been focused on the local failure rather than the whole structural collapse; (2) The probability of unpredictable events has been virtually not considered in structural designs; and (3) The allowable limit/extent of damage is hard to be defined through the probability theory of progressive collapse. As such, they attempted to come up with the principles focused on anti-progressive collapse specifications and standards. Zhang studied the Rachel system installed with horizontal and vertical tension members [17]. The system effectively connected all parts of the structure and increased the structural continuity and ductility. Additionally, the system offered the ability of "cross-bridge" for the structure and would minimize the failure and progressive collapse.

Collapse mechanisms generally consist of three 
parts: collapse mechanism, collapse criterion, and collapse discriminant index [18]. The collapse mechanism research focuses on the process and style of structural collapses under earthquakes. The collapse criterion research emphasizes on the making of a mathematical model for analyzing structural collapses under earthquakes. Collapse criterions have been categorized into five kinds: (1) Deformation criterion, (2) Energy criterion, (3) Low cycle fatigue criterion, (4) Both deformation and energy criterion, and (5) Both deformation and fatigue criterion. Lastly, the collapse discriminant index is a random variable used mainly to define the limit index related to the collapse criterion. The statistical parameter and probability characteristic for this index should be determined in the research of collapse mechanisms. Test simulations and theoretical analysis methods have been used in the structural judgement and component failure criteria under structural collapse process in China. Yi conducted a static test to study the collapse performance of RC frame structures using the stepwise unloading method [19]. His results demonstrate the whole collapse damage process of the frame and provide a guide for numerical analysis and structural design.

Based on the above literature review, although many progressive collapse analysis methods have been proposed, they are too complex to be applied in practice. After partial failure, the upper portion of load-bearing components is under overall stress state. However, current research still focuses on qualitative analysis and virtually has no mentioning of the force mechanism for the upper part of the whole structure. Moreover, the vibration phenomenon caused by the local damage to residual structure is different from the usual dynamic phenomena such as earthquake response. However, it is rare to focus on the progressive collapse dynamic response analysis, and more attention on dynamic progressive collapse and progressive collapse assessment of construction based on dynamic analysis in current literatures. Research related to mega composite structure systems are nearly empty, especially the seismic performance and collapse mechanism issues.

\section{Experimental Research}

There are three common laboratory methods used to test the seismic resistance: pseudo-static testing, pseudo-dynamic testing, and shaking table simulation testing. In comparison, pseudo-static testing generally has the lowest cost due to simple equipment required and convenience to acquire the information on specimen stiffness, bearing capacity, deformation, and energy dissipation. It is mainly used to establish the local mechanical model for mega composite structural systems. Pseudo-dynamic test method combines the advantages of pseudo-static test and shaking table test, enabling better simulation on the seismic responses of large and complex structures. This method is usually applied to regular structural frames rather than mega structures. The shaking table test can reproduce an earthquake process and is the most accurate method for seismic performance test. It is mainly used the rationality of seismic design theories, methods of high-rise buildings. Hence, this method can be extended to study high-rise mega composite structural systems.

In 2006, a shaking table test for reinforced concrete frame to simulate the earthquake was tested by Qinhua Huang [20]. They recorded response time-history and whole collapse process and obtained dynamic characteristics of the structural model and other basic parameters such as frequency and damping ratio every stage. Through these parameters, they analyzed model seismic and collapsed performance under severe earthquake action.

A.Astaneh verified prevention measures when a metal cable was placed in the floor or bottom of a beam. Tests showed that when structure gone to partial damage, cables in the bottom of floors or beams start suspension chain effect, that ensure structural power transmission continuity, until destruction, loads in failure region can be effectively transferred to members which under destroyed, which thereby increasing structural anti-collapse capacity [21].

\section{Numerical Simulation Research}

Newton motion law is cited as the foundation by classical mechanics, which deduced structural dynamic differential equations and established development foundation for numerical methods. When we overview all of research methods in numerical calculation, usually, we divide them into two categories: continuum and non-continuum numerical method. Continuum numerical method gets a rapid development, including variational method, weighted residual method, boundary element method, finite difference method, finite element method and finite strip method, etc. Among them, the finite strip method and boundary element method belongs to the semi-analytical numerical method, finite strip method is generally applicable only in plate, shell and other issues in analysis. However, boundary element method can be applied to an infinite domain analysis, widely used in geotechnical engineering and soil analysis. Additionally, finite element methods are widely used for elastic and elasto-plastic analysis for reinforced concrete frame. In contrast, development of non-continuum numerical methods is slower. However, when unknown field functions (e.g., the displacement field) solved by continuum numerical method is not continuous and cannot be approximately equivalent to the continuity, theoretical basis of continuum mechanics will no longer applicable. At this time, we would like to use non-continuum numerical method, for example, discontinuous deformation analysis (DDA), discrete element method and numerical manifold method (NMM), and sometimes also using finite element method of explicit integration.

A lot of explorations in numerical simulation for building collapse process and collapse analysis under earthquake have been done by many researchers around the world.

In 2006, Xinzheng Lu et al simulated the collapse process of high-rise concrete structure under static 
and dynamic loads and published frame failure mechanism [22]. In addition, they tried to simulate structural steel and concrete with different fibers and got a more accurate material hysteresis curve. Furthermore, soften destruction process of frame under axial force and moment was obtained for bottom columns by using static pushover analysis simulating the deformation and failure process.

In 2008, a multi-layer flat steel frame with failure central column at the ground floor was studied in progressive collapse dynamic analysis by using instantaneous loading testing and ANSYS/LS.DYNA dynamic finite element software by Xiaobin Hu and Jiaru Qian et al [23].

In 2008, two kinds of steel frame structures with eccentric resistance support and a center resistance support were analyzed for collapse by using LS-DYNA by K. Khandelwal et al [24].

In 2011, Yi Liang, Xinzheng Lu et al simulated a three floors reinforced concrete frame about their progressive collapse in accordance with concrete design code in China and referring the design progress of DoD2005 in Unite States. Also, they studied the anti-progressive collapse design for the frame by using Rachel strength method and alternate path method [25].

Through current researches, although collapse simulation has got progress, totally reproduce for whole collapse process is still in infancy. Researches on damage evolution law and structural collapse failure mechanism of high-rise building for mega composite structure system under earthquake action remain to be further in-depth searching, such as stiffness degradation, damage and yield of composite structure etc. Also, relevant theoretical issues for simulation on structural progressive collapse analysis need to be more explored, e.g., discontinuous displacement field of structural members and joint under progressive collapse and failure process, how to simulate these discontinuous displacement field, geometrically nonlinear problems on large rotation and large displacement etc. under structural collapse. Moreover, contact-impact and damping simulation under the collapse process are the difficulties for numerical simulation.

\section{Problems and Suggestions Issues on Collapsed Judging Criterion}

This paper aims to provide current researches status on the collapse mechanism and prevention measures of mega composite structural systems from theoretical research, experimental research to numerical simulation. As mentioned above, although some effective collapsed judgement criterions in specific field has been obtained by researches from the definition of structural qualitative parameters to criteria established using fuzzy mathematics and analyzed the structural collapse based on these researches, it is a further way to approach our ultimate destination. Parallel results, these collapsed judgement criterions are seemingly redundant and complex for whole process analysis, however, our destination of research is to find a structural collapse mechanism which can be applied in real project and get a prevention measures. So we should appropriately simply the collapse mechanism in our research and get a reasonable quantitative analysis model used for more precise simulation and better predict the capacity of prevention in collapse. So as to reveal the mechanism of structural collapse and do further research on reliable forecasting and prevention for progressive collapse.

\section{Researches in the Future}

So far, a large number of experimental studies and numerical simulations have been experienced. And a lot of helpful advices to improve the anti-collapse ability have been obtained. However, the structural design, production and installation are more complex than normal structure for mega composite structure system, due to the giant and complexity, their mechanical behavior, mechanical analysis methods and failure mechanisms are more complex, especially under the randomly severe earthquake. Similarly, because of complexity and uncertainty from mega composite structures, it is a difficult work to get accurately predict for characteristics and dynamics response parameters of buildings. Although, the maximum of the mega composite structural height has been limited by the Current Seismic Design Code of Buildings GB50011-2010 in China, how to carry out specific seismic design and collapse prevention are confused. In addition, there are higher requirements for mega composite structure under seismic performance, costly and relatively centralized personnel and assets, coupled with limited research results in seismic performance, collapse mechanism and prevention measures of mega composite structure, we believe that it is a key scientific and technological cases waiting for solved at the field of high rise building that a more perfect analysis method, damage cumulative model, failure damage criterion, measures to prevent collapse and modified test verification method under earthquake action to be found. Compared with modifying analysis method, we confirm that we should find a more reasonable mathematical tool to describe structural collapse and establish a perfect analysis model in order to carry out the whole process of structure collapse under severe earthquake. Furthermore, it is urgent to do in-depth research on basic theory and failure mechanism under severe earthquake. Corresponding design methods and prevention measures will help to further improve the technological content at the field of high-rise buildings worldwide which will get a significant economic and technical advantage for mega composite structure systems.

\section{References}

1. Sasa He, Zhiwu Yu. (2009). "Summary Seismic Research on Mega-frame Structure". Industrial Construction, 39(5), 101-105.

2. GSA (General Service Administration). (2003). "Progressive Collapse Analysis and Design Guidelines for New Federal Office Buildings and Major Modernization Projects", USA 
3. Dusenberry D O. (2002). "Review of existing guidelines and provisions related to progressive collapse". National Workshop on Prevention of Progressive Collapse in Rosemont, Ill, Washington

4. BSI. (2002). BS 6399-1:1996. "Loading for buildings -Part 1: Code of practice for dead and imposed loads", London.

5. Smith J L. (2003). "Anti-terrorism: criteria, tools \& technology". Vicksburg: Applied Research Associates, Inc.

6. Goode M G. (2004). "Fire protection of structural steel in high-rise buildings". Reston: National Institute of Standards and Technology

7. BRAC. (2003). "Building Regulations Advisory Committee annual report 2002". Office of the Deputy Prime Minister

8. HMSO. (2004). "The Building Regulations 2000: Approved document A -Structure". Norwich: The Stationery Office

9. DOD (Department of Defense). (2005). "Unified facilities criteria, Design of Buildings to Resist Progressive Collapse", USA.

10. Japanese Society of Steel Construction Council. (2005). "Tall Buildings and Urban Habitat Guidelines for Collapse Control Design", Japan

11. Breen, J.E. (1975). "Research Workshop on Progressive Collapse of Building Structures held at the University of Texas at Austin", National Bureau of Standards, Washington, D.C.

12. El lingwood B., Leyendeeker E.V. (1978). "Approaches for Design against Progressive Collapse". Journal of the Structural Division, Proceedings of the American Society of Civil Engineers, 1(104), ST3.

13. D.O.Dusenberry. (2002). Review of Existing Guidelines and Provisions Related Progressive Collapse. From MMC'S July 2002 Workshop on Prevention of Progressive Collapse Multihazard Mitigation Council of the National Institute of Building Sciences, Washington, D.C.

14. Magnusson.J. (2004). Learning from structures subjected to loads extremely beyond design. NASCC (North American Steel Construction Conference), American Institute of Steel Construction, Long Beach, CA.

15. Joonhong Lira and Theodor Kanthammer. (2006). "Progressive Collapse Analysis of 2D Steel-Framed Structures with Different Connection Models". Engineering journal, 3, 201-215

16. Uwe Starosse. (2006). "Progressive collapse of Structure: Nomenclature and Procedures". Structures Engineering International, 16(2): 113-117

17. Lishan Zhang. (2006). Technology research on anti-collapse of steel concrete structure. Master Dissertation of Hebei Polytechnic University.

18. Zuyan Shen, Guoqiang Li. (1992) . Development of Construction design for high-rise building. Journal of Building Structures, 13(4), 75-78.
19. Weijian Yi, Qingfeng He, Yan xiao. (2007). Experimental Study on anti-collapse performance of reinforced concrete frames. Journal of Building Structures, 28(5), 104-109.

20. Qinghua Huang. (2006).Study on Spatial Collapse Responses of Reinforced Concrete Frame Structures under Earthquake. Shanghai, Doctoral Dissertation of Tongji University.

21. Abolhassan Astaneh. (2002). "Use of catenary cables to prevent progressive collapse of buildings", California, University of California Berkeley.

22. Yi Li, Xinzhen, Lu, Lieping Ye. (2012). Numerical model of RC structure on progressive collapse under fire. Engineering Mechanics, 29(4), 96-103.

23. Xiaobin Hu, Jiaru Qian. (2008). Progressive collapse dynamic response analysis of Single-layer Plane Frame. Engineering Mechanics, 25(6), 38-43.

24. Khandelwal K, et al. (2009). "Progressive collapse analysis of seismically designed steel braced frames". J. Constr Steel Res, 65(3), 699-708.

25. Yi Li, Xinzhen, Lu, Lieping Ye. (2011). Research on anti-progressive collapse for reinforced concrete frame structures. Building Science, 27(5), 12-18. 